\title{
Different bacterial gene expression patterns and attenuated host immune responses are associated with the evolution of low-level vancomycin resistance during persistent methicillin-resistant Staphylococcus aureus bacteraemia
}

\author{
Benjamin P Howden*1,2, Danielle J Smith ${ }^{3}$, Ashley Mansell4, \\ Paul DR Johnson ${ }^{2}$, Peter B Ward ${ }^{5}$, Timothy P Stinear ${ }^{1}$ and John K Davies ${ }^{1}$
}

Address: ${ }^{1}$ Australian Bacterial Pathogenesis Program, Department of Microbiology, Monash University, Clayton, Victoria, Australia, ${ }^{2}$ Infectious Diseases Department, Austin Health, Heidelberg, Victoria, Australia, ${ }^{3}$ Australian Research Council Centre of Excellence in Structural and Functional Microbial Genomics, Monash University, Clayton, Victoria, Australia, ${ }^{4}$ Centre for Functional Genomics and Human Disease, Monash Institute of Medical Research, Monash University, Clayton, Victoria, Australia and ${ }^{5}$ Microbiology Department, Austin Health, Heidelberg, Victoria, Australia

Email: Benjamin P Howden* - Ben.Howden@med.monash.edu.au; Danielle J Smith - Danielle.Smith@med.monash.edu.au; Ashley Mansell - Ashley.Mansell@med.monash.edu.au; Paul DR Johnson - Paul.Johnson@austin.org.au;

Peter B Ward - Peter.Ward@austin.org.au; Timothy P Stinear - Tim.Stinear@med.monash.edu.au;

John K Davies - John.Davies@med.monash.edu.au

* Corresponding author

Published: 27 February 2008

BMC Microbiology 2008, 8:39 doi:10.1/86/147|-2180-8-39
Received: 24 September 2007

Accepted: 27 February 2008

This article is available from: http://www.biomedcentral.com/I47I-2/80/8/39

(C) 2008 Howden et al; licensee BioMed Central Ltd.

This is an Open Access article distributed under the terms of the Creative Commons Attribution License (http://creativecommons.org/licenses/by/2.0), which permits unrestricted use, distribution, and reproduction in any medium, provided the original work is properly cited.

\begin{abstract}
Background: Low-level vancomycin resistance in Staphylococcus aureus (vancomycin-intermediate S. aureus (VISA) and hetero-VISA [hVISA]) emerges during persistent infection and failed vancomycin therapy. Up-regulation of genes associated with the "cell wall stimulon" and mutations in the vraSR operon have both been implicated in the development of resistance, however the molecular mechanisms of resistance are not completely understood. To further elucidate the mechanisms leading to resistance transcriptome comparisons were performed using multiple clinical pairs of vancomycin-susceptible $S$. aureus (VSSA) and hVISA/VISA $(n=5)$, and three VSSA control pairs from hospitalized patients with persistent bacteraemia that did not develop hVISA/ VISA. Based on the transcriptome results multiple genes were sequenced and innate immune system stimulation was assessed in the VSSA and hVISA/VISA pairs.

Results: Here we show that up-regulation of vraS and the "cell wall stimulon" is not essential for acquisition of low-level vancomycin resistance and that different transcriptional responses occur, even between closely related hVISA/VISA strains. DNA sequencing of vraSR, saeSR, $m g r A$, rot, and merR regulatory genes and upstream regions did not reveal any differences between VSSA and hVISA/VISA despite transcriptional changes suggesting mutations in these loci may be linked to resistance in these strains. Enhanced capsule production and reduced protein $A$ expression in hVISA/VISA were confirmed by independent bioassays and fully supported the transcriptome data. None of these changes were observed in the three control pairs that remained vancomycinsusceptible during persistent bacteremia. In a macrophage model of infection the changes in cell surface structures in hVISA/VISA strains were associated with significantly reduced NF- $\mathrm{kB}$ activation resulting in reduced TNF- $\alpha$ and IL-I $\beta$ expression.
\end{abstract}


Conclusion: We conclude that there are multiple pathways to low-level vancomycin resistance in S. aureus, even among closely related clinical strains, and these can result in an attenuated host immune response. The persistent infections associated with hVISA/VISA strains may be a consequence of changes in host pathogen interactions in addition to the reduced antibiotic susceptibility.

\section{Background}

Low-level vancomycin resistance in Staphylococcus aureus (vancomycin-intermediate S. aureus [VISA], and heterogenous-VISA [hVISA]) is associated with vancomycin treatment failure and persistent infection [1-4]. The mechanisms underlying hVISA/VISA appear to involve step-wise processes under vancomycin selective pressure $[5,6]$. Global metabolic changes affecting the synthesis and structure of the bacterial cell wall are the major phenotypic features. These include cell wall thickening [7-9] associated with increased production of abnormal muropeptides [10], increased D-ala-D-ala residues and reduced peptidoglycan cross-linking [11], reduced growth rate, and reduced autolytic activity $[8,11,12]$. The thickened cell wall that results is thought to prevent diffusion of vancomycin to its active site in the cytoplasmic membrane [13].

The two-component regulatory system $\operatorname{vraSR}$, was shown to be up-regulated in the Japanese strains Mu50 and Mu3 [14] and the VISA strain JH9 [15]. vraSR is a part of the "cell wall stimulon" that positively modulates cell wall biosynthesis, is induced by cell wall active agents $[16,17]$, and has been suggested to be consistently up-regulated in VISA strains $[15,18]$. It is postulated that the cell wall active glycopeptides stimulate the over expression of the "cell wall stimulon" and promote resistance by increasing cell wall thickness. Recently, the complete genome sequencing of an isolate pair from a single patient demonstrated a small number of mutations associated with the VISA phenotype. Early in the evolution of resistance a mutation in the vraSR operon was detected [6]. Point mutations and inactivation of $a g r$, an important quorum sensing global regulatory system in $S$. aureus, have been previously described in some VISA strains [19], and were associated with higher levels of resistance in strain JH9 [6], but are not a consistent finding. Recently, a number of additional genes were found to be over expressed in VISA strains and selective over-expression of these genes in the vancomycin susceptible strain N315 led to subtle increases in vancomycin resistance [20]. Most studies to date have been performed with in vitro or in vivo laboratory derived strains and the relevance of these findings to clinical infection in humans is unclear. A major limitation of previous studies assessing transcriptional changes in hVISA/VISA strains is that only single pairs of isolates have been used. This has made it difficult to draw conclusions about the relevance of the transcriptional differences in VISA strains as often hundreds of genes were differentially regulated $[15,17,21]$.

We recently characterized five clinical pairs of VSSA and hVISA/VISA, isolated from patients with persistent MRSA bacteremia, and in whom vancomycin treatment failed [12]. These isolates demonstrated phenotypic changes commonly associated with VISA strains, including cell wall thickening and reduced autolytic activity. The level of resistance demonstrated in these strains is more frequently found clinically, as strains with a vancomycin MIC of $\geq 8 \mathrm{mg} / \mathrm{L}$ are still uncommon. In addition, we have obtained three pairs of clinical isolates from patients with persistent MRSA bacteremia and vancomycin treatment failure, in whom low-level vancomycin resistance did not develop. We used microarray analysis to investigate the transcriptional differences in the five VSSA and hVISA/ VISA pairs and the three control pairs to determine if consistent transcriptional changes occur in clinical MRSA isolates associated with persistent bacteraemia and a common level of vancomycin resistance (hVISA/VISA with vancomycin MICs of 2-4 mg/L). Because many patients infected with hVISA/VISA strains have persistent infection, and because of the significant changes in surface structure of these hVISA/VISA strains, the impact of the VISA/VISA phenotype on host-pathogen interactions was also assessed.

Here we demonstrate that transcriptome patterns are divergent in different isolates pairs, and up-regulation of the "cell wall stimulon" and mutations in vraSR are not essential for the expression of vancomycin resistance in hVISA/VISA isolates. In addition we demonstrate for the first time that the hVISA/VISA phenotype is associated with significant changes in the expression of capsule and protein A on the cell surface, and hVISA/VISA strains produce less innate immune system activation.

\section{Results \\ Isolate characteristics}

Five VSSA and hVISA/VISA isolate pairs (pairs 1 to 5) were included in this study as well as 3 control pairs of strains (pairs 6 to 8 ). The reason for including the control pairs was to determine if transcriptional changes are found in MRSA isolates after persistent bacteraemia, but where hVISA/VISA does not develop. If similar transcriptional 
changes were found in the control strains as in the VSSA and hVISA/VISA pairs it would suggest these changes were independent of the resistance mechanism. In the three control pairs (pairs 6 to 8) pulsed field gel electrophoresis (PFGE) demonstrated identical banding patterns for isolate pairs, and identical spa types (JKD6084 and JKD6089, spa type 382; JKD6090 and JKD6094, spa type 382; JKD6095 and JKD6097, spa type 3). All 6 control isolates were fully vancomycin susceptible by population analysis profile testing, and had vancomycin MICs within the susceptible range (Table 1 ).

\section{Microarray analysis of control pairs}

No genes were differentially expressed in pairs 7 and 8 when the later clinical isolate (JKD6094 and JKD6097) were compared to the earlier isolate (JKD6090 and JKD6095). For isolate pair 6 only two genes were differentially expressed; SACOL0935 (D-alanine-activating enzyme/D-alanine-D-alanyl carrier protein ligase), fold ratio 2.32; and SACOL0936 (DltB, a putative activated Dalanine membrane transport protein), fold ratio 2.27 .

\section{Microarray analysis of clinical hVISA/VISA strains}

For the VSSA and hVISA/VISA pairs a list of genes of interest was generated as described in the methods section. These results are presented as the fold ratio of hVISA/VISA compared to the related VSSA isolate. There were 54 genes that were down-regulated, and 89 genes that were up-regulated in at least two isolate pairs. Selected genes from this list which were of particular interest are highlighted in figure 1 and additional file 1 . The complete gene list is also provided in additional file 2. Down-regulation of the quorum sensing global regulator $\operatorname{agr}(\operatorname{agr} A, \operatorname{agr} B)$ was prominent across three pairs. This would be expected to have secondary effects on exotoxin production and expression of cell adhesion molecules, and a number of genes involved in pathogenesis and toxin production, and cell surface adhesion molecules were indeed significantly down-regulated ( $s p a, f n b A, f n b B$, efb, putative exotoxin SACOL0478, fibrinogen-binding protein related proteins and precursors SACOL1164 and SACOL1169). Of particular note, marked down-regulation of the spa gene SACOL0095 was demonstrated in four of the five hVISA/ VISA isolates, and another IgG-binding protein, SACOL2418 was down-regulated in all five isolates.

Table I: Study isolates and susceptibility results

\begin{tabular}{|c|c|c|c|c|}
\hline \multirow[t]{2}{*}{ Isolate } & \multirow[t]{2}{*}{ Phenotype $^{a}$} & \multicolumn{2}{|c|}{$\mathbf{M I C b}(\mu \mathrm{g} / \mathrm{ml})$} & \multirow[t]{2}{*}{ Reference or Comment } \\
\hline & & VCM & TEIC & \\
\hline \multicolumn{5}{|l|}{ Pair I } \\
\hline JKD 6000 & VSSA & 2.0 & 0.5 & {$[12]$} \\
\hline JKD 6001 & VISA & 4.0 & 8.0 & {$[12]$} \\
\hline \multicolumn{5}{|l|}{ Pair 2} \\
\hline JKD 6009 & VSSA & 1.0 & 0.5 & [12] \\
\hline JKD 6008 & VISA & 4.0 & 2.0 & {$[12]$} \\
\hline \multicolumn{5}{|l|}{ Pair 3} \\
\hline JKD 6021 & VSSA & 1.0 & 0.25 & [12] \\
\hline JKD 6023 & VISA & 4.0 & 8.0 & {$[12]$} \\
\hline \multicolumn{5}{|l|}{ Pair 4} \\
\hline JKD 6052 & VSSA & 1.0 & 0.5 & {$[12]$} \\
\hline JKD 6051 & hVISA & 2.0 & 4.0 & [12] \\
\hline \multicolumn{5}{|l|}{ Pair 5} \\
\hline JKD 6004 & VSSA & 1.0 & 0.5 & {$[12]$} \\
\hline JKD 6005 & hVISA & 2.0 & 4.0 & {$[12]$} \\
\hline \multicolumn{5}{|c|}{ Pair 6 (control) } \\
\hline JKD 6084 & VSSA & 0.5 & $\leq 0.25$ & [this study] \\
\hline JKD 6089 & VSSA & 1.0 & $\leq 0.25$ & [this study] \\
\hline \multicolumn{5}{|c|}{ Pair 7 (control) } \\
\hline JKD 6090 & VSSA & 0.5 & $\leq 0.25$ & [this study] \\
\hline JKD 6094 & VSSA & 0.5 & $\leq 0.25$ & [this study] \\
\hline \multicolumn{5}{|c|}{ Pair 8 (control) } \\
\hline JKD 6095 & VSSA & 1.0 & 0.5 & [this study] \\
\hline JKD 6097 & VSSA & 1.0 & 0.5 & [this study] \\
\hline \multicolumn{5}{|c|}{ Other Isolates } \\
\hline $\mathrm{PI}$ & & & & Cap8 positive [57] \\
\hline Newman & & & & Cap5 positive [57] \\
\hline
\end{tabular}

aVSSA, vancomycin-susceptible S. aureus; VISA, vancomycin-intermediate S. aureus; hVISA, hetero-VISA.

bMinimum inhibitory concentration. VCM, vancomycin; TEIC, teicoplanin. 


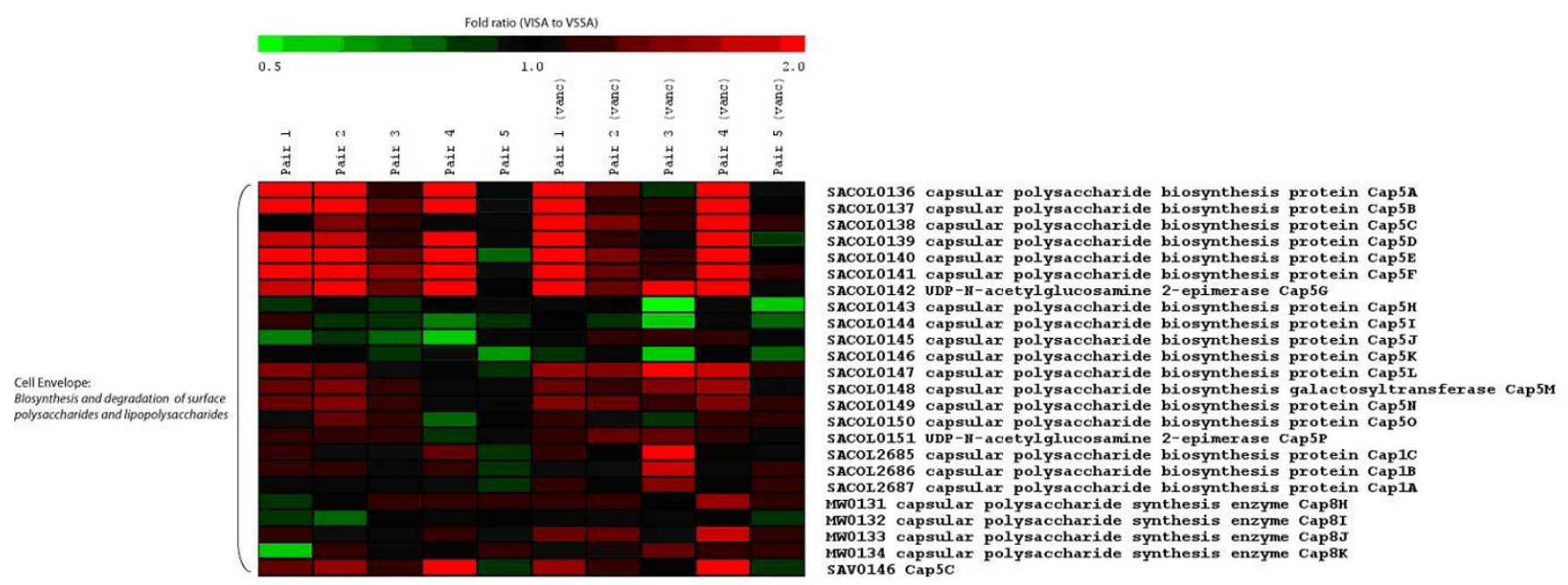

\section{Figure I}

Heat map analysis of selected genes. Heat map analysis of selected genes which were differentially expressed in at least 2 isolate pairs. The results are expressed as fold ratio of gene expression for hVISA/VISA compared to VSSA. Results are presented for all 5 isolate pairs without antibiotic exposure and all 5 isolate pairs after exposure to vancomycin. This figure shows the upper quartile of these selected genes, for the full image please see additional file I.

A number of contiguous genes were up-regulated. This included genes involved in urease production and nitrogen metabolism (ureA, ureB, ureC, ureD, ureE, ureF, ureG, narG, narH, nirD) and amino acid biosynthesis for aspartate (hom, lysC, asd, dapA, dapB, dapD). In addition genes encoding pyruvate biosynthesis were also up-regulated (ilvB, ilvC, ilvE, leuA). Of particular interest was the up-regulation of capsular polysaccharide biosynthesis genes (cap5A, cap5B, cap5D, cap5E, cap5F) in a number of hVISA/VISA isolates. The gene encoding the SceD protein (SACOL2088, a putative transglycosylase) was frequently up-regulated. Regulators other than agr, which had differential expression, included the merR family regulators SACOL2193 and SACOL2517 in 4 and 3 pairs respectively, the GntR family regulator (SACOL1997) in 2 pairs, and up-regulation of a putative regulatory gene (SACOL2585) in 2 pairs, but down-regulation in another pair.

Previous studies have demonstrated significant transcriptional changes in $S$. aureus isolates when compared to non-exposed isolates, after exposure to vancomycin. We therefore exposed both the susceptible and hVISA/VISA isolate in pairs 1 to 5 to vancomycin for $30 \mathrm{~min}$ prior to RNA extraction and microarray analysis, in an effort to detect differences in responses to vancomycin exposure in hVISA/VISA and VSSA isolates from the same pair. After exposure of the VSSA and hVISA/VISA in each pair to vancomycin there was a more pronounced gene down-regulation compared to the initial analysis (Figure 1, and additional file 2). This included significant down-regulation across 3 of the 5 pairs in the 2-component system
saeSR, and marked down-regulation of MW2407 encoding a hypothetical protein in multiple pairs, suggesting that vancomycin led to differential effects in gene regulation between the hVISA/VISA isolate and VSSA in each pair. There were however, no consistent effects of the vancomycin exposure across all isolate pairs.

A heat map analysis was also performed to assess global changes in all VSSA and hVISA/VISA isolate pairs, using the complete microarray data sets. The heat map of all microarray data (additional file 3) demonstrates that although there are some consistent changes across a few of the isolate pairs (in a small subset of genes, such as genes encoding capsule production, protein A, and urease production), there are significant differences in the global transcriptional patterns in different hVISA/VISA isolates, such that the global transcriptional patterns were divergent between different isolate pairs.

\section{Genes associated with the "cell wall stress stimulon" are not consistently up-regulated in hVISA/VISA}

Because of the recent interest in the importance of up-regulation of the "cell wall stimulon" in hVISA/VISA, linked with cell wall thickening and resistance, we specifically analyzed the transcriptional changes in these genes. Two isolates pairs demonstrated up-regulation of vraS and associated genes in the initial microarray analysis, but of particular interest was the lack of any significant change in two pairs (pair 1 and 5), and the down regulation in the another pair (pair 3) (Figure 2). After vancomycin exposure a number of these cell wall genes were also down reg- 


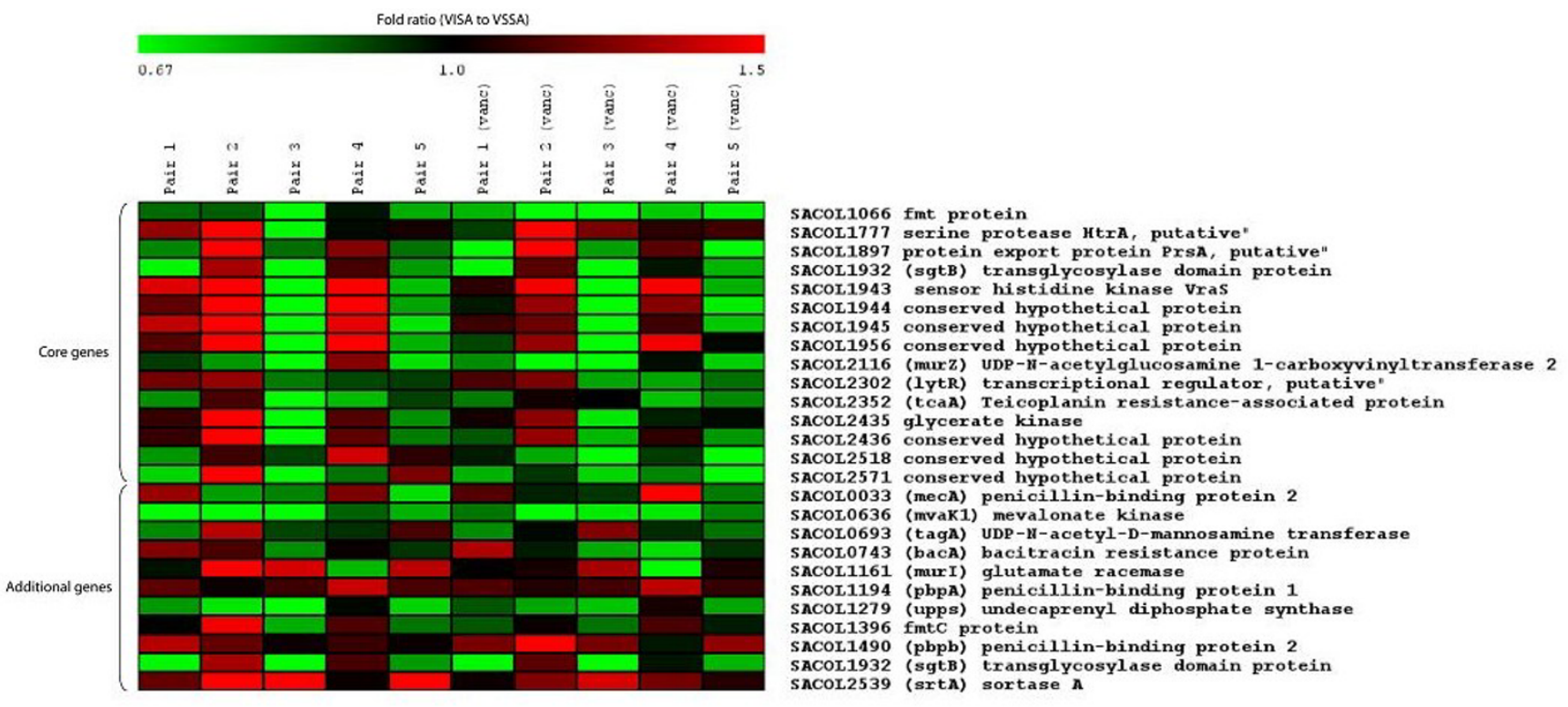

Figure 2

Heat map analysis of cell wall genes. Heat map analysis of "core cell wall genes" and additional cell wall genes which have been commonly shown to be important in cell wall biosynthesis [56]. The results are expressed as fold ratio of gene expression for hVISA/VISA compared to VSSA. Results are presented for all 5 isolate pairs without antibiotic exposure and all 5 isolate pairs after exposure to vancomycin.

ulated in pair 5 (SACOL1066, SACOL1943, SACOL1944, SACOL2116, SACOL2571).

\section{Protein expression and capsule production correlate with array results}

To determine if the transcriptional changes that were detected in hVISA/VISA isolates resulted in changes in protein $A$ and capsule production, as well as urease activity, expression was determined for all isolates. A significant decrease in protein A production was demonstrated for 4 of the 5 pairs (Figure 3 ). For the $5^{\text {th }}$ pair, protein $A$ production was low in both isolates. Urease activity was higher for the hVISA/VISA isolates compared to the VSSA isolates for 4 of the 5 pairs (Table 2). These results correlated well with spa and ureA gene expression (Table 2, Figure 3, additional file 2). A PCR was designed to determine the capsule genotype of isolates (capsule type 5 or capsule type 8). All isolates from pairs 1 to 5 were capsule type 8 strains by PCR. Capsule immunoblot confirmed the PCR capsule typing results, and demonstrated a significant increase in capsule expression in 4 of the 5 pairs (Figure 4). The last pair (no 5) had minimal capsule expression in the VSSA or hVISA strain, and these results also correlated well with microarray data.

\section{Sequencing of regulatory genes does not demonstrate mutations leading to altered regulatory gene expression} In an effort to identify any genetic mutations leading to the resistant phenotype in the 5 hVISA/VISA strains, regulatory loci which were differentially expressed in the microarray experiments or which were predicted to be linked to the microarray results were sequenced in all 5 VSSA and hVISA/VISA pairs. We found no sequence changes between the VSSA and hVISA/VISA in each pair in the two-component regulators saeSR and $\operatorname{vraSR}$, nor in the genes encoding the merR-like regulators SACOL2193 and SACOL2517. The regulatory genes $m g r A$ (SA0641) and rot (repressor of toxins) were also sequenced. Although $m g r A$ was not differentially expressed on the microarray results, it has recently been shown to be an important global regulator in S. aureus, with effects on autolytic activity, protein A expression and capsule production [22]. rot is a sarA homologue which is blocked by RNAIII [23,24]. It has effects on expression of multiple genes, including those involved in synthesis of urease, protein $\mathrm{A}$, and ABC transporters [25]. Again, no mutations were found in either gene. Finally, because of the dramatic decrease in MW2407 expression in the vancomycin exposure experiments, the region MW2406 to MW2408 was sequenced (this gene on the TIGR version $S$. aureus array is unique to MW2). The expected product size based on the MW2 genome was $2898 \mathrm{bp}$, but the amplified fragment from our strains was $\sim 1900 \mathrm{bp}$. There were no differences in the 
A

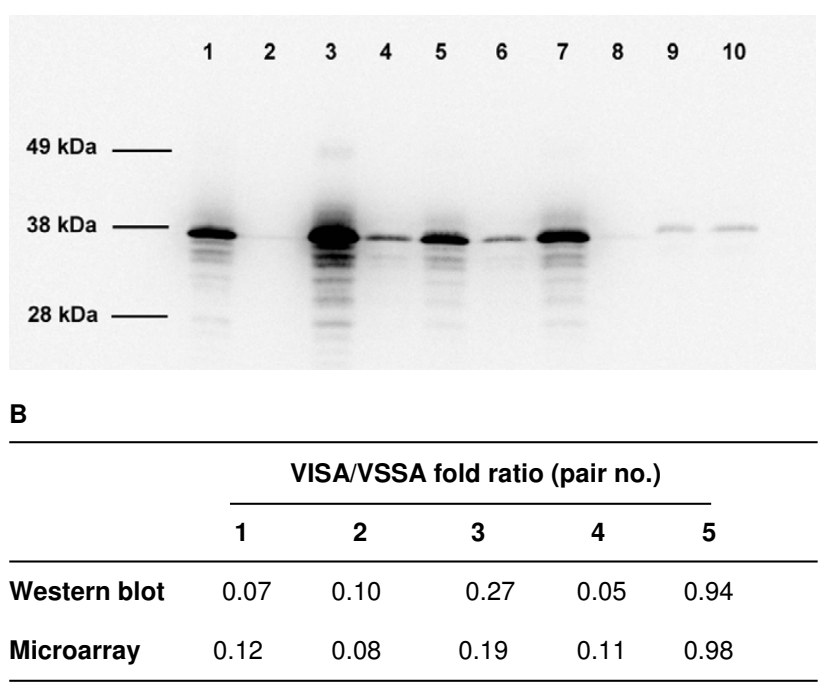

Figure 3

Western blot analysis of protein A production. Analysis of protein A production by Western Blot in hVISA/VISA and VSSA pairs. A. Pair I (lane I, JKD 6000; lane 2, JKD 600I), pair 2 (lane 3, JKD 6009; lane 4, JKD 6008), pair 3 (lane 5, JKD 602I; lane 6, JKD 6023), pair 4 (lane 7, JKD 6052, lane 8, JKD 605I), pair 5 (lane 9, JKD 6004; lane 10, JKD 6005). B. Fold ratios for protein $A$ production and protein A (spa) gene expression for 5 hVISA/VISA and VSSA pairs.

sequences between the VSSA and hVISA/VISA strains. The region amplified in our strains matched closely to 2 regions in MRSACOL encoding tandem lipoproteins and a hypothetical protein (SACOL2496, SACOL2498 and SACOL2492, SACOL2493).

\section{Increasing vancomycin resistance is associated with} reduced NF- $\kappa$ B activation and reduced pro-inflammatory cytokine release

Because we detected a number of significant changes in staphylococcal surface structures that interact with the innate immune system during the evolution of hVISA/ VISA, we next wished to establish if hVISA/VISA displayed a decreased activation of the prototypic inflammatory transcription factor NF- $\mathrm{BB}$. As shown in Figure 5, there was a statistically significant decrease in NF- $\kappa B$ activation demonstrated with 4 of the 5 hVISA/VISA isolates compared to their parent VSSA strain, particularly at lower concentrations. This appeared to correlate with the vancomycin MIC result, with reduced NF- $\kappa$ B activation detected with all the strains with a vancomycin MIC of $4 \mathrm{mg} / \mathrm{L}$, but only with one of those with an MIC of $2 \mathrm{mg} / \mathrm{L}$. To determine the biological impact of this effect, a single pair (JKD6021 and JKD6023) were selected to determine if the reduced NF- $\kappa \mathrm{B}$ activation resulted in a diminished expres-
P1

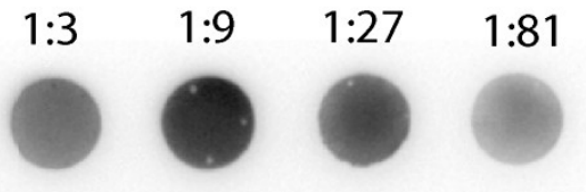

Newman

JKD6000

JKD6001

JKD6009

JKD6008

JKD6021

JKD6023

JKD6052

JKD6051
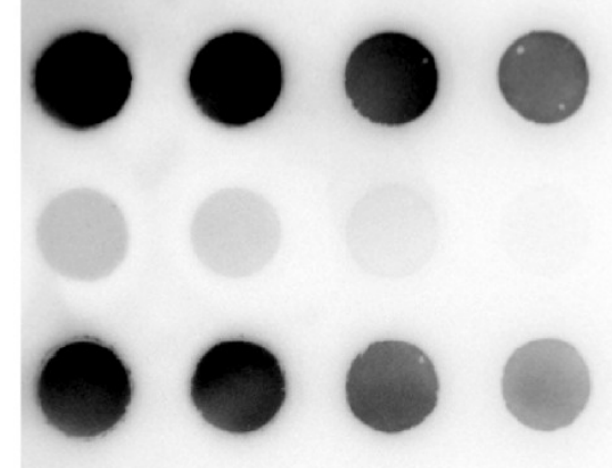

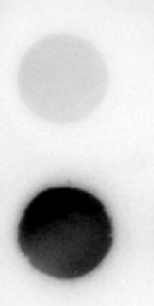
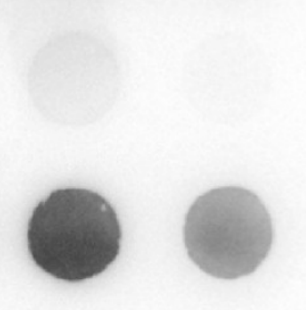

\section{JKD6004}

\section{JKD6005}

\section{Figure 4}

Capsule immunoblot comparison of VSSA to hVISA/ VISA. Capsule immuoblot using anti-capsule type 8 antibody. Serial 3-fold dilutions of crude capsule extracts were loaded onto nitrocellulose membrane. Positive control, capsule type 8 positive strain $\mathrm{PI}$; negative control, capsule type 5 positive strain Newman. 
Table 2: Urease assay results and comparison to microarray results

\begin{tabular}{|c|c|c|c|}
\hline \multirow[b]{2}{*}{ Strain } & \multirow[b]{2}{*}{$\begin{array}{c}\text { Urease activity }(\mu \mathrm{mol} \\
\text { urea } \mathrm{min}^{-1} \mathrm{mg} \text { protein }\end{array}$} & \multicolumn{2}{|c|}{ VISA/VSSA fold ratio } \\
\hline & & $\begin{array}{l}\text { urease } \\
\text { assay }\end{array}$ & $\begin{array}{c}\text { microarray } \\
\quad(\text { ure } A)\end{array}$ \\
\hline \multicolumn{4}{|l|}{ Pair I } \\
\hline JKD 6000 & 0.0 & & \\
\hline JKD 600I & 8.2 & $>8.2$ & $3.75^{*}$ \\
\hline \multicolumn{4}{|l|}{ Pair 2} \\
\hline JKD 6009 & 3.9 & & \\
\hline JKD 6008 & 6.8 & 1.7 & 1.40 \\
\hline \multicolumn{4}{|l|}{ Pair 3} \\
\hline JKD 602I & 3.7 & & \\
\hline JKD 6023 & I7.1 & 4.6 & $1.82 *$ \\
\hline \multicolumn{4}{|l|}{ Pair 4} \\
\hline JKD 6052 & 3.8 & & \\
\hline JKD $605 I$ & 5.17 & 1.5 & $2.69 *$ \\
\hline \multicolumn{4}{|l|}{ Pair 5} \\
\hline JKD 6004 & 2.3 & & \\
\hline JKD 6005 & 1.5 & 0.65 & 0.73 \\
\hline
\end{tabular}

Abbreviations: VSSA, vancomycin-susceptible S. aureus; VISA, vancomycin intermediate $S$. aureus.

*Microarray fold ratios were statistically significant.

sion of the NF-kB-dependent inflammatory cytokines TNF- $\alpha$ and IL-1 $\beta$. As demonstrated in Figure 6, after 6 hours exposure to both strains, there was a significant decrease in TNF- $\alpha$ expression when comparing JKD6021 to JKD6023 ( $p<0.001)$, while IL-1 $\beta$ expression was substantially decreased.

\section{Discussion}

Methicillin-resistant Staphylococcus aureus (MRSA) is on the rise globally $[26,27]$, with recent failures of vancomycin therapy for MRSA infections associated with low-level resistance to glycopeptides $[3,28]$. In addition, persistent MRSA bacteremia despite vancomycin therapy has also been recognized as an important clinical syndrome which is incompletely understood [29]. We have investigated transcriptional changes in five clinical pairs of VSSA and hVISA/VISA isolated from patients with persistent MRSA bacteremia on vancomycin therapy. Multiple gene expression changes were found in the hVISA/VISA strains compared to the parent VSSA, but essentially no changes were found in three control pairs of strains, suggesting the transcriptional changes in the hVISA/VISA strains are linked to resistance. Despite the different PFGE patterns [12], the five isolate pairs are closely related as determined by sequence based typing (by multi-locus sequence typing all are ST239-MRSA) [data not shown] and 4 of the 5 isolate pairs have identical spa types [12]). Although there were some consistent transcriptional changes found, there were very few consistent changes across all pairs, suggesting that multiple transcriptional pathways lead to low-level
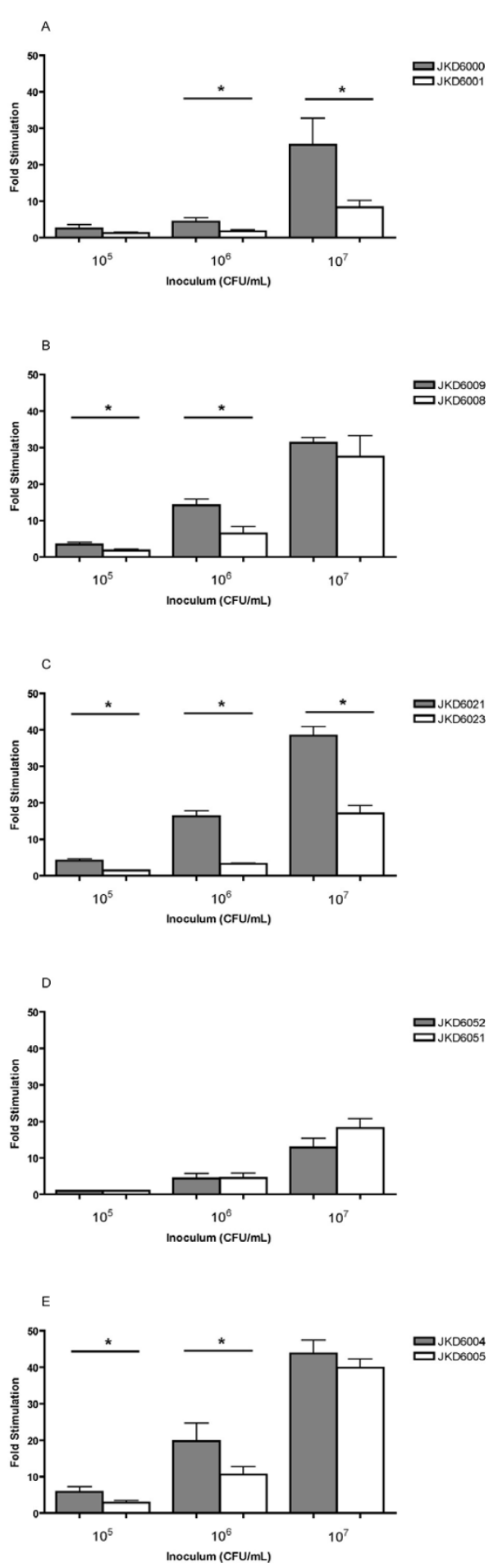

Figure 5

NF- $\kappa B$ activation results for VSSA and $h$ VISA/VISA isolate pairs. Stably transfected RAW cells with an ELAMNF-kB reporter construct were exposed to formaldehyde killed VSSA and hVISA/VISA pairs for 6 hours. Results are presented as fold NF- $\mathrm{kB}$ activation for hVISA/VISA compared to VSSA and are the result of multiple replicates. $(* p<0.05)$ 

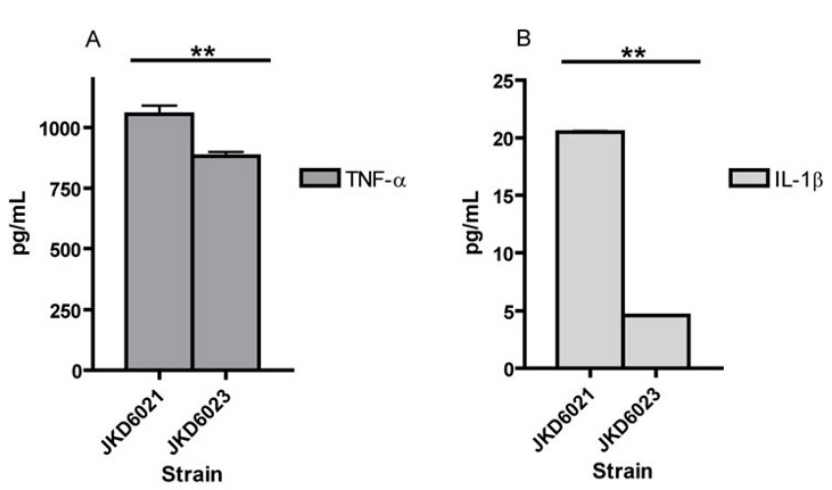

Figure 6

TNF- $\alpha$ and IL-I $\beta$ expression. TNF- $\alpha$ and IL-I $\beta$ expression from RAW264.7 cells after 6 hours exposure to formaldehyde killed JKD602I (VSSA) and JKD6023 (VISA). (** $p<$ $0.00 \mathrm{I})$.

vancomycin resistance in S. aureus, and this is further supported by the detailed analysis of "cell wall stimulon" activation in our strains. These results are most clearly demonstrated by the global heat map analysis (additional file 3 ) that displays the major differences in the transcriptional patterns among the isolate pairs. In addition, we have demonstrated for the first time that the development of low-level vancomycin resistance in patients with persistent bacteraemia is associated with changes in the cell surface and alterations in the host immune response. These are important findings demonstrating that $S$. aureus strains evolve to alter immune system activation, in association with changes leading to reduced response to vancomycin therapy.

A consistent theme from other studies of VISA strains has been the up-regulation of cell wall biosynthetic genes $[14,15,18,21]$, including the vraSR two-component regulatory system and genes from this regulon. It is hypothesized that vancomycin activates the "cell wall stress stimulon" which then remains activated in VISA strains even after the vancomycin is removed. However, by examining multiple clinical isolates, we have established that low-level vancomycin resistance can be acquired in $S$. aureus without up-regulation of vraSR and other genes of the "cell wall stimulon". In fact, these genes were downregulated in one VISA strain (JKD6023) in the initial analysis and in another strain (JKD6005) after vancomycin exposure. This is an important finding that clearly demonstrates that the hVISA/VISA phenotype can develop in clinical S. aureus isolates (associated with cell wall thickening and reduced autolytic activity [12]) without a sustained induction of the "cell wall stimulon". In addition, despite recent data suggesting that mutations in the vraSR operon are common in VISA strains [6], we found no mutations in this region in our strains. It is important to note that our hVISA/VISA isolates are all the same MLST type, and therefore are not from significantly different genetic backgrounds. This suggests that different pathways to resistance exist, even in genetically closely related strains, but that our results may not however apply to strains of other genetic backgrounds, such as Mu50 and Mu3.

Recent studies have highlighted some of the difficulties in interpreting microarray data without analysis of the effects the transcriptional changes on the expression of gene products [30]. We addressed this issue by quantitating a number of the gene products which were differentially expressed in the hVISA/VISA isolates. The microarray data was supported by protein A production, capsule expression and urease activity analysis. In addition, our previous real-time PCR analysis of RNAIII expression correlates well with the decreased agr expression found in the microarray analysis [12]. The increased capsule expression and reduced protein A production demonstrated in 4 of the 5 hVISA/VISA strains is of interest. These changes are likely to have significant implications for host pathogen interactions, and in fact, could favor persistent infection. For this reason, we performed experiments to determine the impact of the hVISA/VISA phenotype on immune system activation, as measured by NF- $\mathrm{KB}$ activation.

We have clearly demonstrated that the development of VISA is associated with changes in NF- $\mathrm{KB}$ activation, which will affect the host pro-inflammatory response to infection. This was clearly demonstrated with the 3 VISA strains that had a vancomycin MIC of $4 \mathrm{mg} / \mathrm{L}$, and one of the strains with a vancomycin MIC of $2 \mathrm{mg} / \mathrm{L}$ (Figure 5). Although hVISA/VISA strains may have slower growth rates compared to VSSA, we controlled for this in our NF$\kappa \mathrm{B}$ activation assays by growing cells to stationary phase and performing colony counts so that equivalent inoculums of killed cells were used in the assays. Many different staphylococcal components activate the innate immune system and induce NF- $\kappa \mathrm{B}$ activation; including protein A, teichoic acids and peptidoglycan [31]. The activation of $\mathrm{NF}-\kappa \mathrm{B}$ in turn up-regulates the expression of pro-inflammatory cytokines including TNF- $\alpha$ and IL-1 $\beta$. The biological impact of this altered immune response was further highlighted by using the strain pair JKD6021 and JKD6023 which confirmed that RAW cells exposed to VISA strains compared to VSSA isolates display a reduced TNF- $\alpha$ and IL- $1 \beta$ expression. Secreted exotoxins also activate innate immune responses, and although we did not measure these directly, the down-regulation of agr in hVISA/VISA strains, including our strains, would also limit immune activation by reducing exotoxin production. The cell surface changes we demonstrated in our 
hVISA/VISA isolates more closely associate to the altered host responses demonstrated here.

Our results confirm the potential importance of changes in the agr two-component regulatory system in hVISA/ VISA strains $[32,33]$. Recently, reduced agr function has been demonstrated in isolates from patients with persistent MRSA bacteraemia where vancomycin resistance was not demonstrated $[29,34]$. Although we have demonstrated reduced agr expression in a number of our strains previously by real time PCR [12] and now by microarray analysis, we did not find any changes in agr expression in isolates from patients with persistent bacteremia without hVISA/VISA. This suggests that there is a link between reduced agr expression and low-level vancomycin resistance, but that reduced agr expression is not always associated with prolonged MRSA bacteraemia and vancomycin therapy as previously suggested [29,34].

Although up-regulation of capsule genes has been demonstrated in other VISA strains $[15,20]$ enhanced capsule production has never previously been confirmed. Loss of capsule typability has been reported in VISA revertant strains obtained by serial passage [35], and electron microscopy of VISA strain JH9 demonstrates what is probably excess capsule [11], however the potential importance of capsule expression in the hVISA/VISA phenotype has not been considered. Over-expression of staphylococcal capsular polysaccharide type 8 has been shown to protect against in vitro opsonophagocytic killing by human neutrophils and lead to more persistent blood stream and organ infection in mice [36]. Recently, up-regulation of capsule gene expression has been documented as part of the global transcriptional response that contributes to innate immune system evasion [37]. It is conceivable that the changes in capsule expression are an adaptation to allow the bacteria to persist in the blood stream and evade immune system killing. It has also been shown that $S$. aureus with increased capsule are less adherent to epithelial cell monolayers, and to damaged heart valves [38], and recently is has been determined that increased capsule expression blocks clumping factor A-mediated binding of staphylococci to fibrinogen and platelets [39]. Therefore the increased capsule changes we observed may play a role in the reduced biofilm formation that we have previously demonstrated in these same strains [12], possibly by masking important adhesins involved in the early stages of biofilm formation. It is also worth considering if the increased capsule production could directly contribute to the low-level vancomycin resistance in some hVISA/ VISA strains, or interfere with the agr quorum sensing system, and explain the quorum sensing changes observed in these hVISA/VISA strains (reduced agr expression), especially as mutations in the agr operon were not found in the strains [12]. More work is needed to determine if increased capsule expression is common in many hVISA/ VISA strains, and to understand the impact of capsule production on the expression of low-level vancomycin resistance in $S$. aureus, and on the agr system.

Down-regulation of spa is one of the most consistent transcriptional changes found in hVISA/VISA strains $[14,15,17,33,40]$. We have shown by western blot that reduced spa expression leads to almost complete absence of protein A expression in hVISA/VISA strains. In addition, consistent down-regulation of the gene encoding another IgG-binding protein (Sbi) was also found. These changes are likely to have significant biological implications, and could partly explain the changes in NF- $\mathrm{kB}$ activation. Protein $\mathrm{A}$ is a major surface protein of $S$. aureus. It binds to the Fc region of IgG, and the Fab portion of Ig belonging to the $\mathrm{VH} 3+$ gene family [41] where it may act as a $B$ cell superantigen, but also binds to several other proteins including $\mathrm{gC} 1 \mathrm{qR}$ which is expressed on activated platelets [41]. Protein A triggers platelet aggregation [42], and along with other staphylococcal surface proteins (such as fibronectin binding proteins [FnBPs]) has been shown to activate platelets $[43,44]$. Upon activation platelets release platelet microbiocidal proteins (PMPs) [45]. The interaction between $S$. aureus and platelets, and in particular the role of PMPs in protection against intravascular infections, and the link between hVISA/VISA and reduced susceptibility to PMP has been well described $[29,32]$. The decreased protein A and FnBPs expression seen in our hVISA/VISA strains would be expected to lead to less platelet activation. Recently, protein A has also been shown to activate a respiratory epithelial inflammatory response by binding to TNR- $\alpha$ receptor 1 [46]. Staphylococcal protein Sbi is an IgG- and $\beta_{2}$ glycoprotein Ibinding protein that has been found to be up-regulated after exposure to human serum [47]. Decreases in spa expression were not seen in the 3 control pairs of strains. Nonetheless, along with increased capsule expression the spa changes have the potential to alter immune system response to infection and promote persistent infection.

Increased urease activity has not been reported in hVISA/ VISA strains. Urease is involved in the urea cycle and amino acid metabolism as well as purine metabolism [48]. The reasons for the increased production of urease in our hVISA/VISA strains is not clear, but may be linked to increased amino acid biosynthesis, with increased expression of genes involved in aspartate biosynthesis in particular found in the microarray analysis. Recently, upregulation of urease production has been demonstrated in $S$. aureus biofilms, and it was hypothesized that increased ammonium and/or ammonia is required to counteract the acid environment in the biofilm. It is not clear how this may be linked to the hVISA/VISA phenotype, except that increased energy requirements and increased metab- 
olism in the hVISA/VISA cell may require increased urease activity.

Sequencing of a number of regulatory genes that were differentially expressed in the microarray analysis ( $\mathrm{raSR}$, saeSR, SACOL2193, SACOL2517) or were potentially involved in the changes we found ( $\mathrm{mrgA}$ and rot) revealed no nucleotide changes. However, any mutations associated with resistance in these strains are clearly leading to global transcriptional changes in hVISA/VISA isolates. The recent work by Mwangi et al [6] demonstrated that a small number of mutations could lead to an increase in vancomycin MIC up to $4 \mathrm{mg} / \mathrm{L}$ in the strain they studied. In our previous study of these VSSA and hVISA/VISA clinical isolates we demonstrated by PFGE a difference in banding patterns for the pairs JKD6000/JKD6001 and JKD6021/ JKD6023 [12]. A genomic microarray comparison using the whole genome of MRSACOL and selected unique genes from S. aureus strains Mu50, MW2 and N315 (TIGR version 2 array) failed to reveal any genetic changes in these pairs [12]. Because the aims of this study were to determine transcriptional changes using the TIGR ver2 arrays, we have not been able to provide any further explanation for the difference in PFGE banding patterns. It is possible that loss of phage DNA could explain the changes, and is unlikely to contribute to the resistance phenotype, but confirmation would require a whole genome comparison.

\section{Conclusion}

The emergence of hVISA/VISA from vancomycin-susceptible $S$. aureus can occur by different transcriptional pathways, even in closely related strains, and it appears that up-regulation of the "cell wall stimulon" and mutations in $v r a S R$ are not essential for the generation of hVISA/ VISA. Changes in capsule production and protein A expression frequently accompany the altered antibiotic susceptibility in hVISA/VISA strains, and reduced innate immune activation may be another factor promoting persistence of infection. Further work is required to fully understand the impact of changes in immune recognition of hVISA/VISA strains. Identifying the mutation or mutations leading to resistance in our strains will require a global comparative genomics approach.

\section{Methods}

\section{Bacterial strains, antibiotic susceptibility and molecular typing}

Staphylococcus aureus strains are listed in table 1. All strains were clinical isolates from patients with persistent methicillin-resistant $S$. aureus bacteraemia (blood culture positive after $>7$ days of vancomycin therapy) [12]. Isolate pairs 1 to 5 have been previously well characterized and represent VSSA and hVISA/VISA pairs [12]. Isolate pairs 6 to 8 are blood culture isolates (patients with bacteremia for 8-22 days) where hVISA/VISA was not detected in the later clinical isolate. All isolates were grown in brain heart infusion broth (BHIB) (Oxoid). For the control pairs vancomycin population analysis profile (PAP), vancomycin and teicoplanin broth minimum inhibitory concentrations (MIC), PFGE and spa typing were performed as previously described [12].

\section{Preparation of total RNA}

After overnight growth in BHIB a 1 in 100 dilution was made in $50 \mathrm{ml}$ of BHIB and incubated at $37^{\circ} \mathrm{C}$ with shaking. Exponential-phase culture $(20 \mathrm{ml})$ was added to 10 $\mathrm{ml}$ of an RNA stabilization reagent (RNA later, Qiagen) and allowed to stand for $10 \mathrm{~min}$ after mixing. Total RNA was prepared using the RNeasy Midi Kit (Qiagen) [12]. For vancomycin experiments, vancomycin (Sigma) was added to cultures in early exponential growth (final concentration $0.5 \times \mathrm{MIC}$ ) for $30 \mathrm{~min}$ before RNA extraction.

\section{Preparation of Cy3- and Cy5-dUTP labeled cDNA probe}

Transcription profiling to compare the later clinical isolate (VISA/hVISA for pairs 1 to 5, VSSA for pairs 6 to 8 ) to the related initial clinical isolate (VSSA) was performed for each pair without antibiotics, and repeated after exposure of both the VSSA and hVISA/VISA isolates to vancomycin for pairs 1 to 5. cDNA was synthesized using SuperScript ${ }^{\mathrm{TM}}$ II RNase H-Reverse Transcriptase (Invitrogen) incorporating aminoallyl-dUTP at $42^{\circ} \mathrm{C}$ with the following reaction mixture (RNA $5 \mu \mathrm{g}$, random hexamers 6 $\mu \mathrm{g}$, Superscript II RT $400 \mathrm{U}, 0.5 \mathrm{mM}$ dATP, dCTP, dGTP, $0.2 \mathrm{mM}$ dTTP, $0.3 \mathrm{mM}$ aa-dUTP [Amersham Biosciences]; total volume $30.7 \mu \mathrm{l}$ ). The RNA was hydrolyzed by addition of $10 \mu \mathrm{l} 0.5 \mathrm{M}$ EDTA and $10 \mu \mathrm{l} 1 \mathrm{M} \mathrm{NaOH}$ with incubation at $65^{\circ} \mathrm{C}$ for $15 \mathrm{~min}$, followed by addition of $25 \mu \mathrm{l}$ $1 \mathrm{M}$ Tris (pH 7.0) to neutralize the $\mathrm{pH}$. The cDNA was collected using a QIAquick column (Qiagen) and dried to completion in a vacuum concentrator. The aminoallyllabeled cDNA was resuspended in $4.5 \mu \mathrm{l} 0.1 \mathrm{M}$ sodium bicarbonate buffer ( $\mathrm{pH} 9.3$ ) and incubated at room temperature for 2 hours after addition of Cy3 or Cy5 (Amersham Biosciences) resuspended in $4.5 \mu \mathrm{l}$ DMSO (Sigma). The probe was purified using a microcon-30 column. The quantity of cDNA and incorporation ratio of Cy dye was measured by spectrophotometry (NanoDrop ND-1000, NanoDrop Technologies, DE, USA) to confirm acceptable results and then the two differentially labeled probes were mixed and dried to completion in a vacuum concentrator.

\section{Array hybridization and analysis}

Array hybridization, washing and scanning using version 2 Staphylococcus aureus microarray slides (The Institute for Genomic Research, MD, USA) was performed as described previously [12]. Briefly, $30 \mu \mathrm{l}$ of hybridization mixture containing Cy3- and Cy5-dUTP labeled probe, $15 \mu \mathrm{l}$ formamide (Sigma), $5 \times$ SSC, $0.1 \%$ SDS, and $22.5 \mu \mathrm{g}$ herring 
sperm DNA (Promega) was denatured at $95^{\circ} \mathrm{C}$ then applied to the microarray slide and incubated overnight at $42^{\circ} \mathrm{C}$. The microarray was washed sequentially in $2 \times \mathrm{SSC}$, $0.1 \%$ SDS; $0.1 \times$ SSC, $0.1 \%$ SDS; and $0.1 \times$ SSC and then dried. The microarrays were scanned with the GMS418 Array scanner (Genetic MicroSystems) to measure the fluorescence of the Cy3 and Cy5 labeled cDNA hybridized to the microarray. The images were combined and quantification of fluorescent and background intensity determined using ImaGene ${ }^{\mathrm{TM}}$ ver 5.1 (Biodiscovery).

RNA extraction and hybridizations were performed in triplicate, and the dye swapped with each replicate. Using BASE [49] the data from the three biological replicates were combined and analyzed using Bioconductor and in particular Limma [50]. After global lowess normalization the log-ratios for each array were scaled so that the median absolute deviation was the same between arrays. For each gene ID a fold ratio of later clinical isolate (hVISA/VISA for pairs 1 to 5 ) compared to the earlier clinical isolate (VSSA) was calculated. Using a moderated t-test P-values were calculated and adjusted for multiple testing using false-discovery-rate (FDR). $\mathrm{A} \geq 1.5$-fold change and $\mathrm{P}$ value $<0.05$ was considered significant. For the hVISA/ VISA comparison any genes which were consistently up or down regulated across at least two clinical pairs was included in the set of "genes of interest". Heat maps of the normalized microarray results were generated using $\mathrm{MeV}$ [51].

\section{Protein Extraction}

Cell wall associated proteins for protein A quantification were extracted as previously described [52]. Isolates were grown in BHIB in an identical manner as described for RNA extractions. Thirty $\mathrm{ml}$ of exponential stage culture was placed in a falcon tube and centrifuged at $5000 \times \mathrm{g}$ for $10 \mathrm{~min}$. After removal of the supernatant $600 \mu \mathrm{l}$ of extraction buffer (30\% raffinose in $0.05 \mathrm{M}$ Tris [pH 7.5] with $0.145 \mathrm{M} \mathrm{NaCl}$ ) containing lysostaphin (Sigma) (250 ug), $10 \mu \mathrm{g}$ of DNase (Sigma), $1 \mathrm{mg} \mathrm{ml}^{-1}$ iodoacetamide (Sigma), and $1 \mathrm{mM} \mathrm{ml}^{-1}$ phenylmethylsulfonyl fluoride (Sigma) was added. The mixture was incubated for $1 \mathrm{~h}$ at $37^{\circ} \mathrm{C}$ with rotation and then centrifuged at $8000 \times \mathrm{g}$ for $10 \mathrm{~min}$, and the supernatant was centrifuged at $8000 \times \mathrm{g}$ for a further $10 \mathrm{~min}$. Cellular protein for assessment of urease activity was extracted from eight $\mathrm{ml}$ of culture. The culture was pelleted, washed in PBS at $4{ }^{\circ} \mathrm{C}$, and resuspended in $1 \mathrm{ml}$ PBS $\left(4^{\circ} \mathrm{C}\right)$. The cells were disrupted in a FastPrep $^{\mathrm{TM}}$ FP120 (Bio101 Savant, CA, USA) (setting 6 for $45 \mathrm{sec} \times 2$ ) and the tube was centrifuged at $12,000 \times \mathrm{g}$ for $30 \mathrm{~min}$ at $4^{\circ} \mathrm{C}$. The supernatant was transferred to a new tube. Protein concentrations were measured using the BCA protein assay kit (Pierce, IL, USA) and stored in aliquots at $-80^{\circ} \mathrm{C}$.

\section{SDS-PAGE and western blot analysis for protein A expression}

Fifteen $\mu \mathrm{g}$ of cell wall associated protein from each isolate was separated in a $12 \%\left(\mathrm{wt} \mathrm{vol}^{-1}\right)$ SDS-PAGE gel. The protein samples were transferred from the SDS-PAGE gel to cellulose nitrate transfer membrane (Schleicher \& Schuell). A mouse derived monoclonal anti-protein A antibody (2000 $\times$ dilution) (Sigma), and secondary sheep anti-mouse IgG peroxidase conjugate $(2000 \times$ dilution $)$ (Silenus) were used. The blots were developed using the Western Lightening chemiluminescence kit (PerkinElmer) and the image acquired and analyzed using the LAS-3000 Luminescent Image Analysis System (Fujifilm, Tokyo, Japan) and Multi Gauge version 2.2 software (Fujifilm, Tokyo, Japan).

\section{Urease Assays}

Urease activity was measured using a coupled enzyme assay [53]. The $1.5 \mathrm{ml}$ reaction mixture contained $31 \mathrm{mM}$ Tris-HCl (pH 8.0), $10 \mathrm{mM}$ urea (Amresco, OH, USA), 810 $\mu \mathrm{M}$ 2-oxoglutarate (Sigma), $240 \mu \mathrm{M}$ NADH and $1.34 \mathrm{mg}$ glutamate dehydrogenase (Sigma). Reactions were performed at room temperature and NADH degradation was measured by absorbance at $340 \mathrm{nM}$ using a 552 UV-VIS spectrophotometer (Perkin-Elmer). The urease activity of each isolate was expressed as $\mu \mathrm{mol}$ of urea hydrolyzed $\min ^{-1}$ mg of protein ${ }^{-1}$.

\section{Capsule typing and Quantification}

A multiplex PCR for capsule genotyping (CP5 and CP8) was designed using sequences available in NCBI (accession numbers for cap5, U811973; cap8, U73374). The forward primer was in Cap5/8G and the reverse primers in the variable regions, Cap5 $\mathrm{H}$ and $\mathrm{Cap} 8 \mathrm{H}$ (Table 3). The CP8 positive strain P1 and the CP5 positive strain Newman were used as controls. For capsule quantification a capsule immunoblot was performed [36]. Crude capsule extracts were prepared after growth in BHIB for $18 \mathrm{~h}$ at $37^{\circ} \mathrm{C}$, using a previously described method [54]. After adjusting the OD 600 to $0.5,10 \mathrm{ml}$ of culture was pelleted, resuspended in $500 \mu \mathrm{lBS}$, then treated with the following enzymes consecutively at $37^{\circ} \mathrm{C}$; lysostaphin (sigma) $200 \mu \mathrm{g} \mathrm{ml}^{-1}$ for $15 \mathrm{~min}$; DNase I (sigma) $300 \mathrm{U} \mathrm{ml}^{-1}$ for 15 min; and proteinase $\mathrm{K}$ (sigma) $100 \mu \mathrm{g} \mathrm{ml}^{-1}$ for $1 \mathrm{~h}$, and then inactivated at $75^{\circ} \mathrm{C}$ for $10 \mathrm{~min}$. Serial dilutions were loaded onto nitrocellulose membrane using a dot-blot apparatus. After blocking with 5\% skim milk the membrane was incubated with CP8-specific rabbit antiserum kindly provided by Jean Lee, and then sheep anti-rabbit IgG peroxidase conjugate (Chemicon, Australia). The blots were developed as described above.

\section{DNA techniques}

Genomic DNA was extracted using the GenElute Bacterial Genomic DNA Kit (Sigma). PCR was carried out using Taq 
Table 3: Primers used in study

\begin{tabular}{ll}
\hline $\begin{array}{l}\text { mgrA } F \\
\text { mgrA R }\end{array}$ & $\begin{array}{l}\text { TTG AAG CAC ATG CAG AAA CA } \\
\text { TCG CAA CAA ACA CAA CCA TT }\end{array}$ \\
mw2406 to 2408 F & CCC AAT CTC CTT GAG CTA CAT T \\
mw2406 to 2408 R & TTA GTT GGT TAG GCC AAT AAA AA \\
saeSR F & GGC GGC ATA CAG TTA ATT TCA \\
saeSR R & CAC TCA TTG TTA AAA CAG ATT TCA CTT \\
vraSR F & TTG TCG GTG CTG AAA TCA AT \\
vraSR R & GTT GCG ACG GAT GAG GTT AT \\
rot F & TGT AGA ATT GTTGCA ATT TAA TGG T \\
rot R & TGC CAA CAA CAA AAA GAG GTT \\
SACOL2193 L & CCT TGA CCT ACT TCA GTT TCA TTT \\
SACOL2193 R & ATA AGA AGT ATT CAA ACG AAG ATG ACA \\
SACOL25I7 L & GCG CTT TCT TTA CGA GCA CT \\
SACOL25I7 R & TGA CGT CGG GTC ATC AAC TA \\
cap5/8G L & TTT TGA AGT TCC CTG GTG TCC \\
cap8H R \\
cap5H R
\end{tabular}

DNA polymerase (Roche Molecular Biochemicals). DNA sequencing was performed using the BigDye Terminator version 3.1 cycle sequencing kits (Applied Biosystems) and the reaction mixtures were analyzed with the 3730 DNA Analyser (Applied Biosystems). Primers for amplifying and sequencing vraSR, saeSR, rot, SACOL2193 and SACOL2517, MW2406 to MW2407, and mgrA (SA0641) were designed using the MRSA COL, MW2 and N315 genome sequences (Table 3 ).

\section{NF- $\kappa$ B assay}

Staphylococcus aureus cells were prepared from stationary phase cultures by washing in cold PBS and resuspending in $5 \%$ formaldehyde for $1 \mathrm{~h}$, followed by additional washes in PBS. Colony counts were performed prior to the addition of formaldehyde, to allow inoculation of equivalent cell numbers in the stimulation assays. Three biological replicates were prepared for each isolate. RAW264.7 mouse macrophage cells stably expressing the NF- $\mathrm{kB}-$ dependent ELAM-luciferase reporter construct were used [55]. Cells were seeded at $2 \times 10^{4}$ cells/well of a 96-well flat bottomed tissue culture plate in $100 \mu \mathrm{l}$ LPS-free media (RPMI plus $0.5 \mathrm{mg} / \mathrm{ml} \mathrm{G} 418$, supplemented with $10 \%$ FCS and $1 \mathrm{mM} \mathrm{L}$-glutamine) and incubated overnight at $37^{\circ} \mathrm{C}, 5 \% \mathrm{CO}_{2}$. Cells were then stimulated with VSSA or hVISA/VISA isolates in triplicate, at a range of concentrations for $6 \mathrm{~h}$ at $37^{\circ} \mathrm{C}, 5 \% \mathrm{CO}_{2}$. After removing the media $50 \mu \mathrm{l}$ of $1 \times$ Promega passive lysis buffer was added to each well ( $5 \mathrm{~min}$ at room temperature). Twenty $\mu \mathrm{l}$ from each well was transferred to a white opaque $\mathrm{TC}_{96}$ plate, and $30 \mu \mathrm{l}$ Luciferase assay reagent (Promega) added. Luci- ferase activity was measured with a Fluro-Optima luminometer. The statistical significance of the data was evaluated by paired $t$ test using GraphPad Prism 4.0 (GraphPad Software Inc., San Diego, CA).

\section{TNF- $\alpha$ and IL-I $\beta$ immunoassays}

These assays were performed using the Quantikine Mouse TNF- $\alpha$ and IL-1 $\beta$ immunoassay kits (R\&D Systems) according to the manufacturers' instructions. Briefly, RAW 264.7 cells were seeded at $2 \times 10^{4}$ cells/well of a 96-well flat bottomed tissue culture plate in $100 \mu \mathrm{l}$ LPS-free media (RPMI supplemented with $10 \%$ FCS and $1 \mathrm{mM} \mathrm{L-}$ glutamine) and incubated overnight at $37^{\circ} \mathrm{C}, 5 \% \mathrm{CO}_{2}$. Cells were then stimulated with VSSA and VISA in triplicate for $6 \mathrm{~h}$ at $37^{\circ} \mathrm{C}, 5 \% \mathrm{CO}_{2}$. After spinning the plates supernatant from each well was stored at $-20^{\circ} \mathrm{C}$ prior to analysis. The statistical significance of the data was evaluated by paired $t$ test using GraphPad Prism 4.0 (GraphPad Software Inc., San Diego, CA)

\section{Authors' contributions}

BH carried out all the experimental work, except for the assay to assess innate immune responses which were performed by DS. The study was conceived by JD, PJ, BH and AM. PW carried out initial characterization of the strains used in the study. PJ assisted with statistical analysis and TS assisted with assessment of sequencing results. AM, JD and TS assisted $\mathrm{BH}$ with drafting the manuscript. All authors read and approved the final manuscript.

\section{Additional material}

\section{Additional file 1}

Complete figure 1. Full image of heat map analysis of selected genes which were differentially expressed in at least 2 isolate pairs. Click here for file

[http://www.biomedcentral.com/content/supplementary/14712180-8-39-S1.pdf]

\section{Additional file 2}

Data table 1. Summary of microarray results for the hVISA/VISA to VSSA comparison. Any genes which were consistently up or down regulated across at least two clinical pairs were included in the set of "genes of interest". Data are presented as the fold ratio of hVISA/VISA to VSSA. Table $1 a$ and $1 b$ are without vancomycin exposure. Table $1 c$ and $1 d$ are after vancomycin exposure (see methods section for details).

Click here for file

[http://www.biomedcentral.com/content/supplementary/14712180-8-39-S2.pdf] 


\section{Additional file 3}

Global heat map. Heat map analysis for all genes on the microarray. The results are expressed as fold ratio of gene expression for hVISA/VISA compared to VSSA. Results are presented for all 5 isolate pairs without antibiotic exposure and all 5 isolate pairs after exposure to vancomycin. Click here for file

[http://www.biomedcentral.com/content/supplementary/14712180-8-39-S3.pdf]

\section{Acknowledgements}

Benjamin Howden was supported by a Postgraduate Medical and Dental Scholarship from the National Health and Medical Research Council, Australia.

This work was supported by The Australian Bacterial Pathogenesis Program from the National Health and Medical Research Council, and the Australian Research Council Centre of Excellence in Structural and Functional Microbial Genomics, Australia.

Staphylococcus aureus microarray slides were kindly supplied by The Institute for Genomic Research (TIGR), Rockville, MD.

We thank Jean Lee, Brigham and Women's Hospital, Boston for providing capsule antibody, and Timothy Foster, Trinity College, Dublin for supplying control strains.

We also thank members of the Monash Infection and Immunity Network for their assistance.

\section{References}

I. Tenover FC, McDonald LC: Vancomycin-resistant staphylococci and enterococci: epidemiology and control. Curr Opin Infect Dis 2005, 18:300-305.

2. Howden BP, Ward PB, Charles PG, Korman TM, Fuller A, du Cros P, Grabsch EA, Roberts SA, Robson J, Read K, Bak N, Hurley J, Johnson PD, Morris AJ, Mayall BC, Grayson ML: Treatment outcomes for serious infections caused by methicillin-resistant Staphylococcus aureus with reduced vancomycin susceptibility. Clin Infect Dis 2004, 38:521-528.

3. Howden BP, Ward PB, Johnson PD, Charles PG, Grayson ML: Lowlevel vancomycin resistance in Staphylococcus aureus - an Australian perspective. Eur J Clin Microbiol Infect Dis 2005, 24: $100-108$.

4. Walsh TR, Howe RA: The prevalence and mechanisms of vancomycin resistance in Staphylococcus aureus. Ann Rev Microbiol 2002, 56:657-675

5. Hiramatsu K: Vancomycin-resistant Staphylococcus aureus: a new model of antibiotic resistance. Lancet Infect Dis 200I, I: $147-155$

6. Mwangi MM, Wu SW, Zhou Y, Sieradzki K, de Lencastre H, Richardson $P$, Bruce D, Rubin E, Myers E, Siggia ED, Tomasz A: Tracking the in vivo evolution of multidrug resistance in Staphylococcus aureus by whole-genome sequencing. PNAS 2007, 104:945I-9456.

7. Cui L, Ma X, Sato K, Okuma K, Tenover FC, Mamizuka EM, Gemmell CG, Kim MN, Ploy MC, El-Solh N, Ferraz V, Hiramatsu K: Cell wall thickening is a common feature of vancomycin resistance in Staphylococcus aureus. J Clin Microbiol 2003, 41:5-I4.

8. Pfeltz RF, Singh VK, Schmidt IL, Batten MA, Baranyk CS, Nadakavukaren MJ, Jayaswal RK, Wilkinson BJ: Characterization of passage-selected vancomycin-resistant Staphylococcus aureus strains of diverse parental backgrounds. Antimicrob Agents Chemother 2000, 44:294-303.

9. Reipert A, Ehlert K, Kast T, Bierbaum G: Morphological and genetic differences in two isogenic Staphylococcus aureus strains with decreased susceptibilities to vancomycin. Antimicrob Agents Chemother 2003, 47:568-576.

10. Cui L, Murakami H, Kuwahara-Arai K, Hanaki H, Hiramatsu K: Contribution of a thickened cell wall and its glutamine nonamidated component to the vancomycin resistance expressed by Staphylococcus aureus Mu50. Antimicrob Agents Chemother 2000, 44:2276-2285.

II. Sieradzki K, Tomasz A: Alterations of cell wall structure and metabolism accompany reduced susceptibility to vancomycin in an isogenic series of clinical isolates of Staphylococcus aureus. J Bacteriol 2003, I85:7103-7II0.

12. Howden BP, Ward PB, Johnson PD, Stinear TP, Davies JK: Isolates with low-level vancomycin resistance associated with persistent methicillin-resistant Staphylococcus aureus bacteremia. Antimicrob Agents Chemother 2006, 50:3039-3047.

13. Cui L, Iwamoto A, Lian JQ, Neoh HM, Maruyama T, Horikawa Y, Hiramatsu K: Novel mechanism of antibiotic resistance originating in vancomycin-intermediate Staphylococcus aureus. Antimicrob Agents Chemother 2006, 50:428-438.

14. Kuroda M, Kuwahara-Arai K, Hiramatsu K: Identification of the up- and down-regulated genes in vancomycin-resistant Staphylococcus aureus strains Mu3 and Mu50 by cDNA differential hybridisation method. Biochem Biophys Res Commun 2000, 269:485-490.

15. McAleese F, Wu SW, Sieradzki K, Dunman P, Murphy E, Projan S, Tomasz A: Overexpression of genes of the cell wall stimulon in clinical isolates of Staphylococcus aureus exhibiting vancomycin intermediate-S. aureus-type resistance to vancomycin. J Bacteriol 2006, 188: I |20-I I33.

16. Utaida S, Dunman PM, Macapagal D, Murphy E, Projan SJ, Singh VK, Jayaswal RK, Wilkinson BJ: Genome-wide transcriptional profiling of the response of Staphylococcus aureus to cell-wallactive antibiotics reveals a cell-wall-stress stimulon. Microbiology 2003, | 49:27| 9-2732.

17. McCallum N, Karauzum H, Getzmann R, Bischoff M, Majcherczyk P, Berger-Bachi B, Landmann R: In vivo survival of teicoplaninresistant Staphylococcus aureus and fitness cost of teicoplanin resistance. Antimicrob Agents Chemother 2006, 50:2352-2360.

18. Kuroda M, Kuroda H, Oshima T, Takeuchi F, Mori H, Hiramatsu K: Two-component system VraSR positively modulates the regulation of cell-wall biosynthesis pathway in Staphylococcus aureus. Mol Microbiol 2003, 49:807-82I.

19. Sakoulas G, GEliopoulos GM, Moellering RC Jr, Wennersten C, Venkataraman L, Novick RP, Gold HS: Accessory gene regulator (agr) locus in geographically diverse Staphylococcus aureus isolates with reduced susceptibility to vancomycin. Antimicrob Agents Chemother 2002, 46: I 492-1502.

20. Cui L, Lian JQ, Neoh HM, Reyes E, Hiramatsu K: DNA microarraybased identification of genes associated with glycopeptide resistance in Staphylococcus aureus. Antimicrob Agents Chemother 2005, 49:3404-34I3.

21. Scherl A, Francois P, Charbonnier Y, Deshusses JM, Koessler T, Huyghe A, Bento M, Stahl-Zeng J, Fischer A, Masselot A, Vaezzadeh A, Galle F, Renzoni A, Vaudaux P, Lew D, Zimmermann-lvol CG, Binz PA, Sanchez JC, Hochstrasser DF, Schrenzel J: Exploring glycopeptide-resistance in Staphylococcus aureus: a combined proteomics and transcriptomics approach for the identification of resistance-related markers. BMC Genomics 2006, 22:296.

22. Luong TT, Dunman PM, Murphy E, Projan SJ, Lee CY: Transcription Profiling of the mgrA Regulon in Staphylococcus aureus. J Bacteriol 2006, 188: 1899-1910.

23. Oscarsson J, Tegmark-Wisell K, Arvidson S: Coordinated and differential control of aureolysin (aur) and serine protease (sspA) transcription in Staphylococcus aureus by sarA, rot and agr (RNAIII). Int J Med Microbiol 2006, 296:365-380.

24. Geisinger E, Adhikari RP, Jin R, Ross HF, Novick RP: Inhibition of rot translation by RNAIII, a key feature of agr function. Mol Microbiol 2006, 61: 1038-1048.

25. Said-Salim B, Dunman PM, McAleese FM, Macapagal D, Murphy E, McNamara PJ, Arvidson S, Foster TJ, Projan SJ, Kreiswirth BN: Global regulation of Staphylococcus aureus genes by Rot. J Bacteriol 2003, 185:610-619.

26. Zinn CS, Westh H, Rosdahl VT, Sarisa Study Group: An international multicenter study of antimicrobial resistance and typing of hospital Staphylococcus aureus isolates from 21 
laboratories in 19 countries or states. Microb Drug Resist 2004, 10:160-168.

27. Tiemersma EW, Bronzwaer SL, Lyytikainen O, Degener JE, Schrijnemakers P, Bruinsma N, JMonen J, Witte W, Grundman H, European Antimicrobial Resistance Surveillance System Participants: Methicillin-resistant Staphylococcus aureus in Europe, 1999-2002. Emerg Infect Dis 2004, 10:1627-1634.

28. Appelbaum PC: The emergence of vancomycin-intermediate and vancomycin-resistant Staphylococcus aureus. Clin Microbiol Infect 2006, I 2(SuppI I): | 6-23.

29. Fowler VG, Sakoulas G, McIntyre LM, Meka VG, Arbeit RD, Cabell $\mathrm{CH}$, Stryjewski ME, Eliopoulos GM, Reller LB, Corey GR, Jones Lucindo TN, Yeaman MR, Bayer AS: Persistent bacteremia due to methicillin-resistant Staphylococcus aureus infection is associated with agr dysfunction and low-level in vitro resistance to thrombin-induced platelet microbicidal protein. J Infect Dis 2004, 190: I |40-1 |49.

30. Fox PM, Climo MW, Archer GL: Lack of relationship between purine biosynthesis and vancomycin resistance in Staphylococcus aureus: a cautionary tale for microarray interpretation. Antimicrob Agents Chemother 2007, 5 I:1274-1280.

31. Fournier B, Philpott DJ: Recognition of Staphylococcus aureus by the innate immune system. Clin Microbiol Rev 2005 I 8:521-540.

32. Sakoulas G, Eliopoulos GM, Fowler VG Jr, Moellering RC Jr, Novick RP, Lucindo N, Yeaman MR, Bayer AS: Reduced susceptibility of Staphylococcus aureus to vancomycin and platelet microbicidal protein correlates with defective autolysis and loss of accessory gene regulator (agr) function. Antimicrob Agents Chemother 2005, 49:2687-2692.

33. Renzoni A, Francois P, Li D, Kelley WL, Lew DP, Vaudaux P, Schrenzel J: Modulation of fibronectin adhesins and other virulence factors in a teicoplanin-resistant derivative of methicillin resistant Staphylococcus aureus. Antimicrob Agents Chemother 2004, 48:2958-2965.

34. Sakoulas G, Gold HS, Cohen RA, Venkataraman L, Moellering RC Jr, Eliopoulos GM: Effects of prolonged vancomycin administration on methicillin-resistant Staphylococcus aureus (MRSA) in a patient with recurrent bacteraemia. J Antimicrob Chemother 2006, 57:699-704.

35. Boyle-Vavra S, Berke SK, Lee JC, Daum RS: Reversion of the glycopeptide resistance phenotype in Staphylococcus aureus clinical isolates. Antimicrob Agents Chemother 2000, 44:272-277.

36. Luong T, Sau S, Gomez M, Lee JC, Lee CY: Regulation of Staphylococcus aureus capsular polysaccharide expression by agr and sarA. Infect Immun 2002, 70:444-450.

37. Voyich JM, Braughton KR, Sturdevant DE, Whitney AR, Said-Salim B, Porcella SF, Long RD, Dorward DW, Gardner DJ, Kreiswirth BN, Musser JM, DeLeo FR: Insights into mechanisms used by Staphylococcus aureus to avoid destruction by human neutrophils. J Immunol 2005, 175:3907-3919.

38. O'Riordan K, Lee JC: Staphylococcus aureus capsular polysaccharides. Clin Microbiol Rev 2004, I 7:2 I 8-234.

39. Risley AL, Loughman A, Cywes-Bentley C, Foster TJ, Lee JC: Capsular Polysaccharide Masks Clumping Factor A-Mediated Adherence of Staphylococcus aureus to Fibrinogen and Platelets. J Infect Dis 2007, 196:919-927.

40. McCallum N, Spehar G, Bischoff M, Berger-Bachi B: Strain dependence of the cell wall-damage induced stimulon in Staphylococcus aureus. Biochim Biophys Acta 2006, 1760: I475- I 48I.

41. Nguyen T, Ghebrehiwet B, Peerschke El: Staphylococcus aureus protein A recognizes platelet $\mathrm{gClqR/p33:} \mathrm{a} \mathrm{novel} \mathrm{mecha-}$ nism for staphylococcal interactions with platelets. Infect Immun 2000, 68:206I-2068.

42. Hawiger J, Marney SR Jr, Colley DG, Des Prez RM: Complementdependent platelet injury by staphylococcal protein $\mathbf{A}$. J Exp Med 1972, 136:68-80.

43. O'Brien L, Kerrigan SW, Kaw G, Hogan M, Penades J, Litt D, Fitzgerald D, Foster T], Cox D: Multiple mechanisms for the activation of human platelet aggregation by Staphylococcus aureus: roles for the clumping factors ClfA and ClfB, the serineaspartate repeat protein SdrE and protein A. Mol Microbiol 2002, 44: 1033-1044.

44. Fitzgerald JR, Foster TJ, Cox D: The interaction of bacterial pathogens with platelets. Nat Rev Microbiol 2006, 4:445-457.
45. Yeaman MR, Bayer AS: Antimicrobial peptides from platelets. Drug Resist Update 1999, 2:1 16-126.

46. Gomez MI, Lee A, Reddy B, Muir A, Soong G, Pitt A, Cheung A, Prince A: Staphylococcus aureus protein A induces airway epithelial inflammatory responses by activating TNFRI. Nat Med 2004, 10:842-848.

47. Zhang L, Rosander A, Jacobsson K, Lindberg M, Frykberg L: Expression of staphylococcal protein Sbi is induced by human IgG. FEMS Immunol Med Microbiol 2000, 28:21 I-2I8.

48. Resch A, Rosenstein R, Nerz C, Gotz F: Differential gene expression profiling of Staphylococcus aureus cultivated under biofilm and planktonic conditions. Appl Environ Microbiol 2005, 71:2663-2676.

49. Saal LH, Troein C, Vallon-Christersson J, Gruvberger S, Borg A, Peterson C: BioArray Software Environment (BASE): a platform for comprehensive management and analysis of microarray data. Genome Biol 2002, 3:1-6.

50. Smyth GK: Linear models and empirical Bayes methods for assessing differential expression in microarray experiments. Stat Appl Genet Mol Biol 2004, 3:Article 3.

5I. Saeed Al, Sharov V, White J, Li J, Liang W, Bhagabati N, Braisted J, Klapa M, Currier T, Thiagarajan M, Sturn A, Snuffin M, Rezantsev A, Popov D, Ryltsov A, Kostukovich E, Borisovsky I, Liu Z, Vinsavich A Trush V, Quackenbush J: TM4: a free, open-source system for microarray data management and analysis. Biotechniques 2003 , 34:374-378.

52. Cheung AL, Fischetti VA: Variation in the expression of cell wall proteins of Staphylococcus aureus grown on solid and liquid media. Infect Immun 1988, 56: 106 I-1065.

53. Dunn BE, Campbell GP, Perez-Perez GI, Blaser MJ: Purification and characterization of urease from Helicobacter pylori. I Biol Chem 1990, 265:9464-9469.

54. Luong TT, Newell SW, Lee CY: Mgr, a novel global regulator in Staphylococcus aureus. J Bacteriol 2003, 185:3703-37I0.

55. Hume DA, Underhill DM, Sweet MJ, Ozinsky AO, Liew FY, Aderem A: Macrophages Exposed Continuously to Lipopolysaccharide and Other Agonists that Act via Toll-Like Receptors Exhibit a Sustained and Additive Activation Rate. BMC Immunol 200I, 2:II.

56. Sobral RG, Jones AE, Des Etages SG, Dougherty TJ, Peitzsch RM, Gaasterland T, Ludovice AM, de Lencastre H, Tomasz A: Extensive and genome-wide changes in the transcription profile of Staphylococcus aureus induced by modulating the transcription of the cell wall synthesis gene murF. J Bacteriol 2007, I89:2376-2391.

57. Wann ER, Dassy B, Fournier JM, Foster TJ: Genetic analysis of the cap5 locus of Staphylococcus aureus. FEMS Microbiol Lett 1999. 170:97-103.

Publish with Bio Med Central and every scientist can read your work free of charge

"BioMed Central will be the most significant development for disseminating the results of biomedical research in our lifetime. "

Sir Paul Nurse, Cancer Research UK

Your research papers will be:

- available free of charge to the entire biomedical community

- peer reviewed and published immediately upon acceptance

- cited in PubMed and archived on PubMed Central

- yours - you keep the copyright
BioMedcentral 